\title{
No Effect of Subthalamic Deep Brain Stimulation on Intertemporal Decision-Making in Parkinson Patients ${ }^{1,2,3}$
}

\author{
Maayke Seinstra, ${ }^{1}$ Lars Wojtecki, ${ }^{2}$ Lena Storzer, ${ }^{2}$ Alfons Schnitzler, ${ }^{2}$ and ${ }^{\circledR}$ Tobias Kalenscher $^{1}$
}

DOI:http://dx.doi.org/10.1523/ENEURO.0019-16.2016

${ }^{1}$ Comparative Psychology, Institute of Experimental Psychology, Heinrich-Heine University Düsseldorf, 40225

Düsseldorf, Germany, ${ }^{2}$ Institute of Clinical Neuroscience and Medical Psychology, Medical Faculty, Heinrich-Heine University Düsseldorf, 40225 Düsseldorf, Germany

\begin{abstract}
Deep brain stimulation (DBS) of the subthalamic nucleus (STN) is a widely used treatment for the motor symptoms of Parkinson's disease (PD). DBS or pharmacological treatment is believed to modulate the tendency to, or reverse, impulse control disorders. Several brain areas involved in impulsivity and reward valuation, such as the prefrontal cortex and striatum, are linked to the STN, and activity in these areas might be affected by STN-DBS. To investigate the effect of STN-DBS on one type of impulsive decision-making-delay discounting (i.e., the devaluation of reward with increasing delay until its receipt)—we tested 40 human PD patients receiving STN-DBS treatment and medication for at least 3 months. Patients were pseudo-randomly assigned to one of four groups to test the effects of DBS on/off states as well as medication on/off states on delay discounting. The delaydiscounting task consisted of a series of choices among a smaller. sooner or a larger, later monetary reward. Despite considerable effects of DBS on motor performance, patients receiving STN-DBS did not choose more or less impulsively compared with those in the off-DBS group, as well as when controlling for risk attitude. Although null results have to be interpreted with caution, our findings are of significance to other researchers studying the effects of PD treatment on impulsive decision-making, and they are of clinical relevance for determining the therapeutic benefits of using STN-DBS.
\end{abstract}

Key words: deep brain stimulation; intertemporal choice; Parkinson's disease

\section{Significance Statement}

To improve the quality of life of patients with Parkinson's disease, it is important to uncover the cognitive side effects of deep brain stimulation of subthalamic nucleus. In this study, we show no effect of deep brain stimulation on altered impulsive decision-making, measured with a financial delay-discounting paradigm. Our study adds an important piece of information on the cognitive side effects of deep brain stimulation, although further studies are needed to verify our results. 


\section{Introduction}

Parkinson's disease (PD) is characterized by a cell loss in substantia nigra and ventral tegmental area, leading to a reduced level of the neurotransmitter dopamine and abnormal functionality of the basal ganglia. The progressive loss of dopamine results in impaired motor functioning, such as bradykinesia, muscle rigor, and/or resting tremor, as well as in characteristic nonmotor symptoms, including depression and memory deficits. Deep brain stimulation (DBS) of the subthalamic nucleus (STN) is a widely used treatment for the motor symptoms of PD. STN-DBS is usually applied when conventional medication starts to become increasingly ineffective (Deuschl et al., 2006). Although STN-DBS has major benefits in reducing motor symptoms (Deuschl et al., 2006; Wichmann and DeLong, 2006), the side effects of STN-DBS on cognition are often less clear (Demetriades et al., 2011).

Several studies indicate that DBS affects neural activity in surrounding areas, thereby altering the activity of a whole network of brain structures (Chang et al., 2007; Li et al., 2007; McCracken and Grace, 2007; Montgomery and Gale, 2007; Li et al., 2012). Since the STN is connected to a number of basal ganglia nuclei as well as cortical areas, STN-DBS can have widespread effects that are not just limited to motor behavior. Not only motor areas are found to be projecting to the STN, but also brain areas involved in the valuation of choice options, such as the medial/orbital cortex in rats (Maurice et al., 1998) and monkeys (Haynes and Haber, 2013) via the so-called hyperdirect pathway (Nambu et al., 2002), which links the cortex with the basal ganglia via the STN. In addition, the STN can be subdivided into several functional zones that can, according to their structural connectivity, be identified as motor, associative, and limbic regions (Lambert et al., 2012), which are part of corticobasal gangliathalamo-cortical loops involved in emotion, movement, and cognition (Parent and Hazrati, 1995a,b).

Patients have often undergone a long period of dopaminergic medical treatment before DBS is considered as the therapy of choice. Dopaminergic treatment usually consists of the intake of levodopa (L-dopa), a dopamine precursor, and/or dopamine agonists. An increased tendency for impulse control disorders (ICDs), which include

Received January 28, 2016; accepted April 7, 2016; First published May 02, 2016

${ }^{1}$ The authors declare no competing financial interests.

${ }^{2}$ Author Contributions: M.S., L.W., A.S. and T.K. designed research; M.S. and L.S. performed research; M.S. analyzed data; M.S. and T.K. wrote the paper.

${ }^{3}$ The project was funded by internal budgets of T.K.

Acknowledgments: We thank Sonja Ascheid, Nina Kessler, Kerstin Frie, and Marika Biernat, as well as the doctors at the Parkinson Ward at the University Clinic Düsseldorf for their aid and help during data collection.

Correspondence should be addressed to Maayke Seinstra, Institute of Experimental Psychology, Heinrich-Heine University Düsseldorf, Universitaetsstrasse 1, 40225 Düsseldorf, Germany. E-mail: maayke.seinstra@hhu.de. DOI:http://dx.doi.org/10.1523/ENEURO.0019-16.2016

Copyright (C) 2016 Seinstra et al.

This is an open-access article distributed under the terms of the Creative Commons Attribution 4.0 International, which permits unrestricted use, distribution and reproduction in any medium provided that the original work is properly attributed. pathological gambling, compulsive shopping, hypersexuality, and hyperphagia (Weintraub, 2008), can develop in PD patients. These ICDs are associated with dopaminergic treatment, in particular with the use of dopamine agonists (Voon and Fox, 2007; Voon et al., 2011a,b; Raja and Bentivoglio, 2012) as well as L-dopa treatment ( $\mathrm{Zu}$ rowski and O'Brien, 2015).

How STN-DBS affects impulsive behavior is unclear, with reports of increases in both the severity of even the new development of ICDs (Hälbig et al., 2009; Lim et al., 2009; Broen et al., 2011; Moum et al., 2012), as well as the attenuation or disappearance of ICD symptoms after the start of STN-DBS treatment (Witjas et al., 2005; Ardouin et al., 2006; Bandini et al., 2007; Lim et al., 2009; Broen et al., 2011). As the dopaminergic medication intake can usually be decreased after the onset of STN-DBS treatment, the reduction in ICD severity might be due to a decrease in the medication dosage, but other factors, such as electrode placement, stimulation parameters, or patient history may underlie changes in ICD severity too (Zurowski and O'Brien, 2015). Several brain areas connected with the STN are involved in impulsive behavior, including the orbitofrontal cortex and the nucleus accumbens (Cardinal et al., 2001; Kheramin et al., 2002; Kalenscher and Pennartz, 2008). Stimulation of the STN can therefore affect impulsive choice in the following two ways: either by directly altering STN functioning, and/or via indirect moderation of activity in connected areas known to be involved in impulsive decision-making.

Since (case study) reports concerning the effects of therapeutic STN-DBS on ICDs are ambiguous, it is important to uncover exactly how STN-DBS affects impulsive behavior, and in particular impulsive choice. The study presented here focuses on delay discounting (i.e., the devaluation of a reward when its receipt is delayed to a future point in time), which can be seen as a measure of impulsive economic decision-making, and is often used to assess impulsive decision-making (Bickel et al., 2012). Although delay discounting captures only one of the many facets of ICDs, reduced delay sensitivity lies at the heart of most concepts of impulsive choice. To dissociate the putative effects of STN-DBS from the effects of dopaminergic medication on delay discounting, we used a $2 \times 2$ design for DBS (on/off) and medication state (L-dopa on/off).

\section{Materials and Methods}

\section{Participants}

Fifty-four patients with bilaterally implanted stimulation electrodes in the STN were recruited for a screening session at the University Clinic Düsseldorf (Center for Movement Disorders and Neuromodulation, Department of Neurology, Institute of Clinical Neuroscience and Medical Psychology, Heinrich-Heine University Düsseldorf), with the aim of identifying patients with no current severe depression [Beck Depression Inventory (BDI), <20], no indication of dementia [Mattis Dementia Rating Scale (MDRS), >130], and inconspicuous performance in a range of other cognitive and mnemonic tests (see below) for inclusion in the experiment. Forty patients (16 female) 
between 42 and 78 years of age (mean, 62.7 years of age; $\mathrm{SD}, 7.4$ years of age) met the inclusion criteria. Further inclusion criteria were bilateral DBS of the STN for a period of at least 3 months and no preimplant history of major depression.

DBS treatment consisted of bilateral $130 \mathrm{~Hz}$ stimulation, except for two patients who received $174 \mathrm{~Hz}$ stimulation in the right hemisphere and $130 \mathrm{~Hz}$ stimulation in the left hemisphere, two patients who received bilateral $150 \mathrm{~Hz}$ stimulation, and one patient who received unilateral (right) $130 \mathrm{~Hz}$ stimulation. Stimulation intensity was either fixed on voltage $(N=26)$ or amperage $(N=14)$, with voltages ranging between 1.2 and $4.0 \mathrm{~V}$ and amperage ranging between 1.1 and $3.4 \mathrm{~mA}$. Pulse width was set at $60 \mu \mathrm{s}$, with the exception of three patients receiving 62 $\mu \mathrm{s}$ pulses and one patient receiving $65 \mu \mathrm{s}$ pulses. One patient received $60 \mu \mathrm{s}$ in the left hemisphere and $90 \mu \mathrm{s}$ in the right hemisphere. The average time since DBS implantation was 30.0 months (SD, 23.7 months), with a minimum of 3 months and a maximum of 85 months. All but one patient received dopamine replacement therapy, with an L-dopa equivalent dose (LED) ranging from 120 to 1975 (mean, 675; SD, 390). All participants were recruited within a time period of 16 months, during their periodic inpatient visits that lasted at least 2 nights. The year of diagnosis ranged from 1989 until 2012. All participants were instructed in detail about the experimental procedure as well as the payment procedure before they provided written informed consent. The study was approved by the local ethics committee of the Medical Faculty of the Heinrich-Heine University Düsseldorf.

\section{Materials}

During screening, patients performed a range of tests designed to measure mood as well as cognitive and mnemonic traits [MDRS, BDI-II, Quick Delay Questionnaire (QDQ), Baratt Impulsiveness Scale (BIS), South Oaks Gambling Screen (SOGS), and Ardouin Behavior Scale (ABS); see below], along with a delay-discounting task [intertemporal choice task (ICT)], risk attitude measurements (Holt-Laury task), and motor skills assessment [Unified Parkinson's Disease Rating Scale (UPDRS)] during testing sessions. We used the following tests.

\section{Mattis Dementia Rating Scale}

The MDRS was used to test for cognitive deficits (Mattis, 1988). This test is commonly used in clinical settings for older patients and can detect dementia disorders such as Alzheimer's disease. It is subdivided into the following five categories: attention, verbal and motor initiation and preservation, construction, conceptualization, and memory (Lucas et al., 1998). Patients with scores of $<130$ points (of a total of 144 points) were excluded from further testing (Schmidt et al., 1994).

\section{Beck Depression Inventory II}

The German version of the BDI-II (Beck et al., 1996) was used to assess depressive symptoms reported for the previous 2 weeks. It consists of 21 items, and each item is ranked from 0 to 3 . The exclusion criterion was a count of $\geq 20$ points, which is indicative of severe depression.

\section{Quick Delay Questionnaire}

The QDQ was administered to assess subjective delay aversion and delay discounting (Clare et al., 2010). The subjects have to rate five items on delay aversion and five items on delay discounting on a 5-point Likert scale. This questionnaire was added to obtain a baseline selfreported measure of delay discounting/delay aversion.

\section{Barratt Impulsiveness Scale}

The BIS is often used as a measure of impulsivity, and its short German version (BIS-15; Spinella, 2007) has been used in the current study. Fifteen items assess nonplanning, motor, or attention impulsivity (Spinella, 2007). Each item is rated on a 4-point Likert scale. This questionnaire was added to obtain a baseline self-reported measure of impulsiveness.

\section{South Oaks Gambling Screen}

The SOGS (Lesieur and Blume, 1987) consists of 20 items and is commonly used to screen for pathological gambling. In this test, a score of $\geq 5$ is considered as probable pathological gambling. This questionnaire was added to identify and control for problem gambling or gambling tendencies, respectively.

\section{Ardouin Behavior Scale}

This scale was designed to detect changes in mood and behavior in PD patients (Ardouin et al., 2009). This semi-structured interview entails 18 items and is rated in 5 points, from 0 (absent) to 4 (severe). The ABS was used to identify potential addictive tendencies (regarding food or medication intake) that might hint at an ICD.

\section{Unified Parkinson's Disease Rating Scale}

Part III of the Movement Disorder Society-sponsored revision of the UPDRS (MDS-UPDRS-III) was used to assess the severity of motor impairment, as well as the efficacy of the different treatment states. Patients had to perform specific movements and were rated from 0 to 4 on each of 18 items covering tremor, rigidity, posture, agility, and general movement (Goetz et al., 2008). The MDS-UPDRS-III was used to assess differences in motor symptoms between the respective on/off states during sessions.

\section{Intertemporal Choice Task}

The ICT used in this study is a common and well validated task with which to elicit time preferences and measure delay discounting (Kirby and Maraković, 1996; Hardisty et al., 2013). The task consisted of a series of binary choices between a smaller, sooner, and a larger, later monetary reward. Choice items were arranged in six blocks with 11 trials each, with an instruction screen after each block to provide the opportunity to take a short break. Within each block, the amount of the smaller, sooner option varied over trials, while the larger, later option remained constant across trials within a given block. The delays used within each block were specified in the instruction screen before each block. In three blocks, the larger, later reward was fixed at $€ 20$, with the smaller, sooner option ranging from $€ 0$ to $€ 20$ in steps of $€ 2$, presented in randomized order. In the other three blocks, the larger, later reward was fixed at $€ 30$, with the 
a

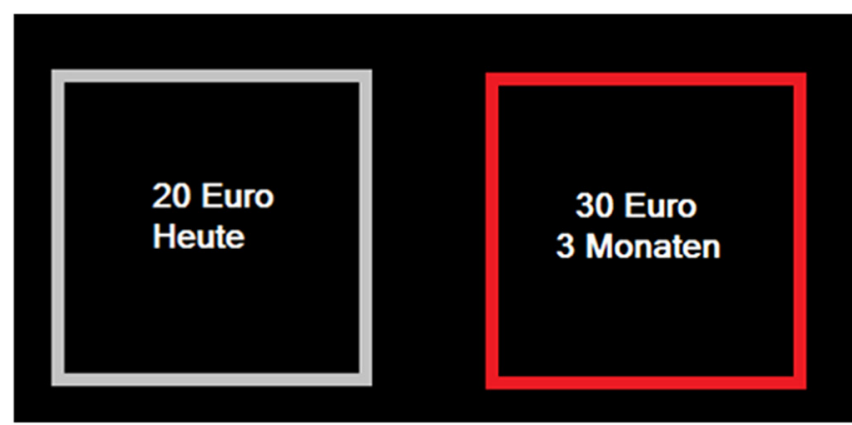

b

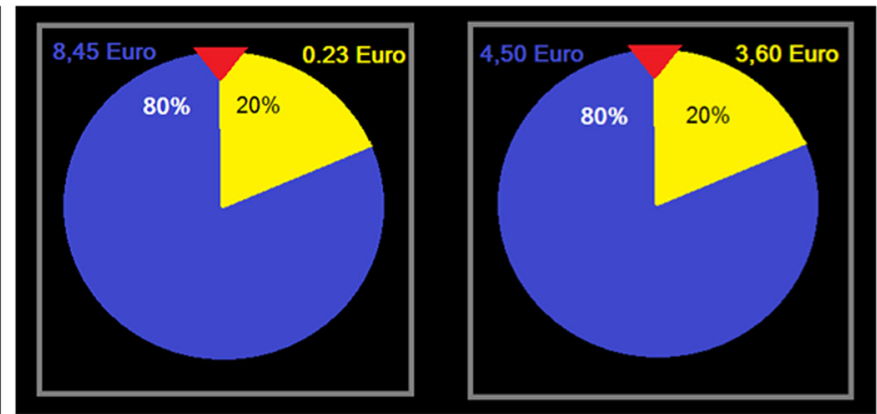

Figure 1. Screenshot of tasks. a, Intertemporal choice task. Participants chose between a smaller reward now or a larger reward later by pressing the $\mathrm{E}$ or I key. When the choice was made, the chosen option was highlighted by a red frame. $\boldsymbol{b}$, Holt-Laury task: participants chose one of two gambles, one considered risky and one considered safer. Lotteries were depicted as wheels of fortune.

smaller, sooner option ranging from $€ 0$ to $€ 30$ in steps of $€ 3$, presented in randomized order. The smaller, sooner option was always immediate. For each of the two large reward amounts, the delay was 3, 6, or 9 months, and the order was randomized across blocks. The options were presented simultaneously on the left and right sides of the screen, and the side of presentation of each choice option was randomized (Fig. 1a). Participants pressed the "E" key to choose the left option and the "l" key to choose the right option. There was no time limit for each choice. The trials with either $€ 0$ "now" or $€ 20 / € 30$ now were considered catch trials, as the choices in these trials indicate whether the participant paid attention or chose rationally. The task was programmed and conducted using the MATLAB (MathWorks) toolbox Cogent. One of the 66 trials was randomly chosen for payment after task performance. Participants received the amount they had selected with the corresponding delay. Both immediate and delayed payment was accomplished by a check that was given either right after the session (immediate payment) or was sent by mail (delayed payment).

\section{Holt-Laury task}

The Holt-Laury task (Holt and Laury, 2002) is a short, thoroughly validated 10-trial task to measure risk attitude (Filippin and Crosetto, 2014). Here, we elicited risk attitude as a control variable as time preference measures may potentially be confounded with risk preference. In each trial, participants chose between two lotteries. In one of the lotteries, the payout was either $€ 8.45$ or $€ 0.23$ with variable probability (riskier lottery); in the other lottery, the payout was either $€ 4.50$ or $€ 3.60$ with the same variable probability (safer lottery). The probability of winning the large reward of each lottery varied from $10 \%$ to $100 \%$ in steps of $10 \%$ across trials in randomized order. Correspondingly, the probability of winning the small reward was $100 \%-p$ (large reward). The probabilities of large and small rewards were identical for both lotteries in a given trial (Fig. 1b). After task performance, the computer randomly picked one trial and played the lottery that was chosen. The outcome was paid by check at the end of the session.

\section{Procedure}

PD patients were recruited and tested during their regular visit to the clinic, which lasted at least 2 nights. After patients were informed about the procedure of our experiment and provided written informed consent, they underwent the screening session in the afternoon on the day of their arrival, or $1 \mathrm{~d}$ after, at the clinic. The screening session involved the mood, memory, and cognition tests outlined above, and lasted $\sim 1 \mathrm{~h}$. During screening, patients were always in their most optimal treatment state (i.e., on-stimulation and on-medication).

To test the effect of DBS and L-dopa on delay discounting, we used a between-subject $2 \times 2$ design with the factors medication (medication on vs off) and STN-DBS (on vs off). Forty patients were randomly assigned to one of the four treatment groups (10 patients/group). The testing procedures were as follows.

A regular visit included an $\sim 16 \mathrm{~h}$ period in which patients refrained from taking medication on either the first or the second night of their stay, starting at about 8:00 P.M. If the test session took place in the on-medication state, patients received $1.5 \times$ their regular dose of L-dopa (but never more than the maximum dosage of $200 \mathrm{mg}$ ), and/or other medication (dopamine agonists; see Table 4), on the morning of the test session, $1 \mathrm{~h}$ before the start of the session, to ensure a robust on-state during the whole procedure. Offmedication testing was always performed in the morning after spending a night without medication.

A test session (for overview, see Fig. 2) took place between 9:00 A.M. and noon, and was conducted by two experimenters, of whom only one knew the current DBS state of the patient (passive experimenter), and the other exclusively interacted with and guided the patient through the session (active experimenter). The test sessions started with switching the DBS state of the patient. To ensure double blindness regarding the DBS state, the stimulator was either turned off or left on by a nurse or doctor who was informed by the passive experimenter, without informing the patient about what was done. The patient was aware that the stimulator would be either turned off or remain on and was informed beforehand about the necessity of the double-blind procedure. At least 50 min after the switch, the MDS-UPDRS-III was 


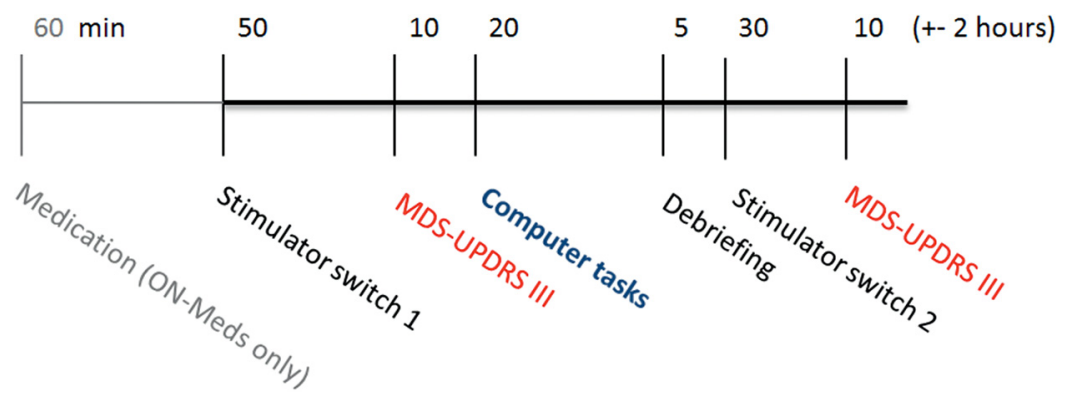

Figure 2. Schematic overview of a session. If patients were tested in the on-medication condition, they received medication (1.5 $\times$ their regular L-dopa dose) 60 min before DBS was switched off or left on. Patients in the off-medication condition had not ingested dopaminergic medication since the previous evening. At the end of a session, a second MDS-UPDRS-III assessment was conducted in the opposite DBS state to confirm DBS effects within subjects.

conducted, followed by the delay-discounting task (ICT) and subsequently the Holt-Laury risk attitude task. Each patient received oral instructions before each task, and was asked control questions to ensure that they understood the tasks. The MDS-UPDRS-III, ICT, and Holt-Laury tasks were completed in $\sim 30-40$ min. Several trials in the tasks were randomly selected for payout (see above). The patient received feedback about the trials chosen for payment immediately after completing the two tasks and was paid accordingly by means of a check. Directly after, the patient was asked about his/her strategy during the choice tasks and was informed about the goal of the experiment. Thirty minutes after changing the stimulation state, a second motor assessment using the MDSUPDRS-III was conducted as a within-subjects control of the DBS state. A within-subjects repetition of the ICT and Holt-Laury task was not conducted because both tasks were deemed to be unsuitable for repeated measures within the short timeframe of one or two mornings.

\section{Data analysis}

We used a $2 \times 2$ between-subjects factorial design with medication (on vs off) and DBS state (on vs off) as independent factors, and choice parameters (see below) as a dependent variable. To estimate discounting parameters in the ICT, we used the following two different, well established models: the hyperbolic discounting model (Mazur, 1984); and the Laibson (1997) quasi-hyperbolic discounting model (see below). In addition, we also used the total number of choices of the smaller, sooner option as a model-free measure of discounting (yielding a value between 0 and 66), as well as a model-free measure of present bias (i.e., the overweighting of immediate outcomes, see below for details). For the Holt-Laury task, we used the switching point [i.e., the probability at which the participant was indifferent between the two gambles (Holt-Laury task indifference points [HL-IPs])]. This measure was obtained using logistic regression. A higher switching point indicated more risk aversion.

\section{Fitting of discounting models}

All mathematical procedures to determine the participants' discount parameters were performed using MATLAB (MathWorks). We first identified the individual IPs (the magnitude of the smaller, sooner reward that renders it equally valuable to the larger, later reward) for each of the six blocks, using logistic regression. This resulted in three values between 0 and 20 for the three blocks with $€ 20$ as maximum reward, and three values between 0 and 30 for the three blocks with $€ 30$ as the maximum reward.

We first fitted the standard hyperbolic model separately to the IPs of blocks 1-3 and blocks 4-6, using the following equation (Mazur, 1984):

$$
\mathrm{SV}_{\mathrm{T}}=\mathrm{A} /(1+k \mathrm{~T}) \text {, }
$$

where $S V$ is the subjective value of the reward at delay $T$ (in months), $A$ is the monetary amount of the reward, and $k$ is the hyperbolic discount parameter describing the steepness of the discount function. The amount was set to $A=1$ as the values were expressed as proportions of the later reward. Larger $k$-values indicate a greater impact of delay on value and therefore steeper discounting. The resulting $k$-values for the $€ 20$ and $€ 30$ blocks were subsequently log transformed and averaged to obtain one $k$-value per individual (note that the correlation between the two $k$-values for the $€ 20$ and $€ 30$ blocks was very high; $r=0.96, p<0.000$ ).

Further, the Laibson quasi-hyperbolic $\beta-\delta$ model was separately fitted to the indifference points of blocks $1-3$ and 4-6 to obtain measures of present bias and patience, as follows:

$$
\begin{gathered}
S V_{T=0}=1 \\
S V_{\mathrm{T}>0}=\beta \times \delta^{\top} .
\end{gathered}
$$

$S V_{t}$ is the subjective value of a reward at time $T$. This equation models the often observed initial rapid decline in subjective value with small delays (present bias) separately, represented by the parameter $\beta$ (with $0 \leq \beta \leq 1$ ). The inverse of $\beta$ can be interpreted as the extra weight added to immediacy, thus smaller $\beta$ values can be construed as stronger present bias. The discount rate of the discount function is $\log (1 / \delta)$. Thus, the parameter $\delta$ (with 0 $\leq \delta \leq 1$ ) can be interpreted as a measure of patience, with higher $\delta$ values indicating higher patience. The resulting $\beta$ and $\delta$ parameters for the $€ 20$ and $€ 30$ blocks were subsequently averaged to obtain one $\beta$ and $\delta$ value for each participant [note that there was a strong correlation 
Table 1. Demographic, screening and questionnaire results per DBS/Med state

\begin{tabular}{|c|c|c|c|c|c|c|}
\hline & \multicolumn{4}{|c|}{ State (MED/DBS) } & \multicolumn{2}{|l|}{ Statistics } \\
\hline & $\begin{array}{l}\text { (1) On/On } \\
(N=8)\end{array}$ & $\begin{array}{l}\text { (2) On/Off } \\
(N=7)\end{array}$ & $\begin{array}{l}\text { (3) Off/On } \\
(N=10)\end{array}$ & $\begin{array}{l}\text { (4) Off/Off } \\
(N=7)\end{array}$ & $F$ (p value) & $\begin{array}{l}\text { Post hoc test } \\
\text { (Gabriel) }\end{array}$ \\
\hline Age (years) & $66.5(1.4)$ & $57.1(1.4)$ & $63.5(2.6)$ & $64.7(2.9)$ & $3.00(0.047) *$ & Group 1 vs 2: \\
\hline Months receiving DBS & $30(8.6)$ & $20(5.1)$ & $30(8,6)$ & $39(10.0)$ & $0.75(0.534)$ & \\
\hline LED & 594 (209.4) & 671 (118.0) & 623 (120.3) & $642(125.0)$ & $0.04(0.988)$ & \\
\hline MDRS & $139(1.2)$ & $138(1.6)$ & $138(1.1)$ & $138(1.3)$ & $0.19(0.902)$ & \\
\hline BIS-nonplanning & $9.3(1.0)$ & $11.9(0.5)$ & $11.5(1.2)$ & $8.1(1.1)$ & 2.74 (0.062) & $p=0.055$ \\
\hline BIS-motor & $8.9(1.1)$ & $10.0(1.3)$ & $11.1(0.6)$ & $8.4(0.8)$ & $1.66(0.197)$ & \\
\hline BIS-attention & $7.6(0.9)$ & $10.4(1.0)$ & $9.9(0.6)$ & $8.4(0.8)$ & $2.54(0.076)$ & \\
\hline QDQ-total & $22.9(2.5)$ & $24.9(2.0)$ & $26.0(1.8)$ & $20.3(2.1)$ & $1.40(0.264)$ & \\
\hline QDQ-discounting & $11.1(1.4)$ & $12.0(1.1)$ & $12.5(1.0)$ & $10.6(1.5)$ & $0.48(0.698)$ & \\
\hline QDQ-Aversion & $11.8(1.3)$ & $12.9(1.5)$ & $13.5(1.6)$ & $9.7(1.3)$ & $1.30(0.294)$ & \\
\hline
\end{tabular}

$* p<0.05$.

between the $\beta$ values of the $€ 20$ and $€ 30$ blocks ( $r=$ $0.83, p<0.000)$ and the $\delta$ values $(r=0.59, p<0.000)]$.

The model fits were performed for each participant individually, using a least-squares algorithm implemented in MATLAB R2013a (MathWorks). The fitting parameters $k, \beta$, and $\delta$ were allowed to vary freely. We calculated the Akaike Information Criterion (AIC) for each model per participant to check the goodness of fit of each model. We then averaged the scores across all participants, resulting in one average AIC value for the hyperbolic model and another AIC value for the Laibson quasi-hyperbolic model. These AIC scores showed that, in general, the data were better described by the quasi-hyperbolic model (mean, -17.5) than the standard hyperbolic model (mean, -10.1). However, when comparing individual AIC values, the quasi-hyperbolic model had higher AIC values compared with the hyperbolic model in 10 participants, indicating a better fit of the hyperbolic model in these participants.

To obtain an additional, model-free measure of present bias, we used the following formula:

Present bias $(P B)=($ large reward -3 months IP $) /(6$ months IP -9 months IP). To obtain an overall measure, we averaged the model-free present bias measure for the $€ 20$ and $€ 30$ blocks (PB). A higher score indicated more present bias.

\section{Statistical analysis}

The statistical analyses reported below were performed using the IBM software package SPSS Statistics 20. We mainly used standard ANOVAs and ANCOVAs to investigate the main effects of DBS and medication state, as well as their interaction on the dependent variables described above. When necessary, we selected the Gabriel pairwise comparisons test as the post hoc test, which is robust against differences in group sample size. Furthermore, we used Bayesian statistics (Wagenmakers, 2007; Masson, 2011) to calculate the evidence in favor of the null hypothesis.

\section{Results}

\section{Subject demographics and trait variables}

Data from eight participants were excluded as they chose the dominated alternative on $>6$ of the 12 catch trials in the ICT (i.e., they selected $€ 0$ now over $€ 20 /$ $€ 30$ later; or they selected $€ 20 / € 30$ later over the same reward now; see above). In addition, two of these participants scored $\geq 5$ points on the SOGS, indicating potential pathological gambling behavior. Our results do not change when these subjects are included in our analysis, except when explicitly mentioned below. Table 1 shows the general descriptive statistics of the remaining 32 patients. The DBS-on group consisted of 18 participants, of whom 8 were tested in the onmedication state. The DBS-off group consisted of 14 participants, of whom 7 were tested in the onmedication state. There was no significant difference in any of the demographic parameters between DBS and medication groups, except for age $\left(F_{(3,28)}=3.00, p=\right.$ 0.047, $\eta^{2}=0.24$; Table 1).

Table 1 shows the descriptive statistics of the screening tasks and questionnaires. A one-way ANOVA showed a significant difference between the groups in the selfreported impulsiveness (BIS-total), $F_{(3,28)}=4.34, p=$ $0.012, \eta^{2}=0.317$. However, Gabriel post hoc tests showed no significant differences between groups: group 1 versus 2 : mean difference $=-6.54, p=0.157$; group 1 vs 3: mean difference $=-6.75, p=0.084$; group 1 vs 4: mean difference $=0.75, p>0.999$; group 2 vs 3 : mean difference $=-0.21, p>0.999$; group 2 vs 4 : mean difference $=7.50, p=0.107$; group 3 vs 4 : mean difference $=7.50, p=0.055$. Nevertheless, we included BIS-total scores as a covariate in all subsequent analyses to account for potential group differences in impulsiveness. Note that all participants filled out the questionnaires in their optimal (on-medication, onstimulation) state, so this difference in BIS-total scores reflects a trait difference between groups, not the effect of DBS on impulsiveness. 


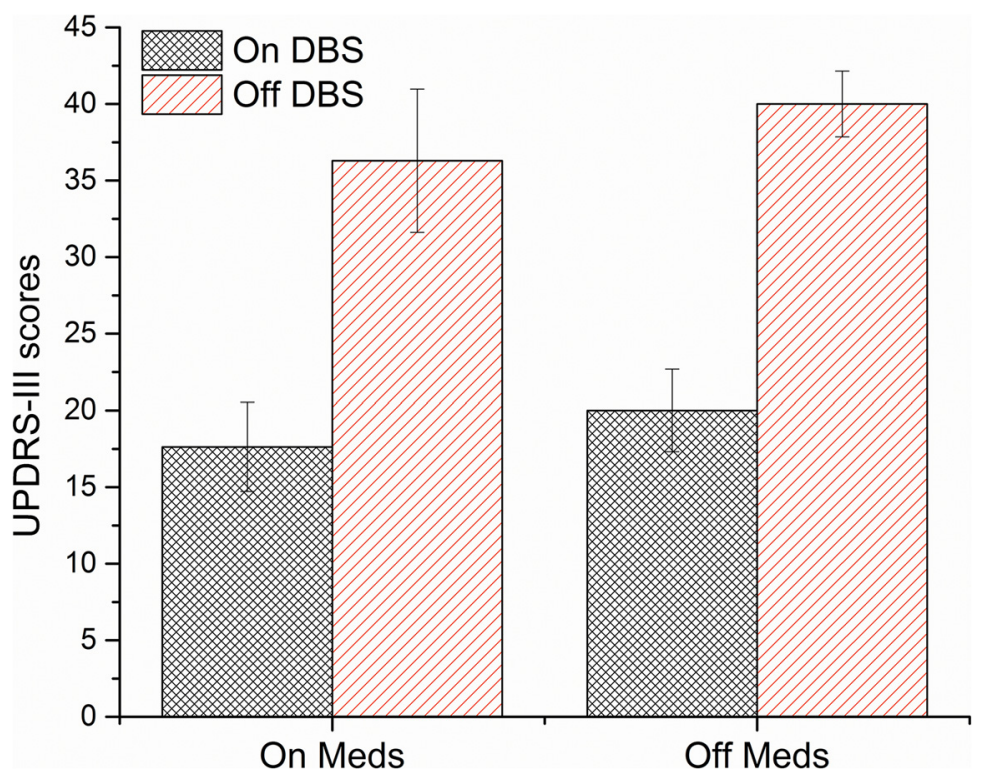

Figure 3. MDS-UPDRS-III scores for each DBS and medication state. Higher scores indicate greater motor impairments. Error bars show SEs.

\section{Differential treatment effects on motor scores, but not delay discounting}

As expected, MDS-UPDRS-III scores were significantly different between DBS/medication states, $F_{(3,28)}=11.96$, $p<0.001, \eta^{2}=0.56$ (Fig. 3). Post hoc tests revealed a significant difference between DBS states (group 1 vs 2 , 0.002 ; group 3 vs $4, p \leq 0.001$ ), whereas no significant difference was observed between medication states (group 1 vs $3, p=0.993$; group 2 vs $4, p=0.990$ ). This is likely due to relatively high interindividual differences in motor scores obscuring the relatively small but often beneficial effect of medication treatment within subjects. Comparing the MDS-UPDRS-III scores within patients (DBS on vs off only) also showed a significant improvement of motor symptoms with stimulation, time $\times$ DBS interaction $\left(F_{(1,31)}=138.84, p<0.001, \eta^{2}=0.82\right)$. Over- all, this indicates that DBS significantly improved motor symptoms in our sample, while medication did not.

Table 2 shows the discounting parameters $k, \beta$, and $\delta$, the number of impulsive choices (NImp), the model-free measure of PB, as well as the HL-IPs within each group. We used a two-way ANOVA to test for the effects of DBS and medication on discounting and risk parameters, as well as on their interaction. We found no significant main or interaction effects of DBS or medication on any of the discounting parameters (Table 2). Figure $4, A$ and $B$, shows the discounting curves for each medication/DBS state for $€ 20$ and $€ 30$ blocks, respectively. Figure 4, C and $D$, shows the median fits of the hyperbolic and quasihyperbolic models, respectively, as well as the 25 th and 75th percentile borders, for each DBS state. Figure 5 shows the total number of impulsive choices for each

Table 2. Delay-discounting parameters and risk measure per DBS/Medication state

\begin{tabular}{|c|c|c|c|c|c|c|c|c|c|c|}
\hline & \multicolumn{4}{|l|}{ DBS } & \multicolumn{4}{|l|}{ Medication } & \multicolumn{2}{|l|}{ Interaction } \\
\hline & On & Off & ANOVA & ANCOVAa & On & Off & ANOVA & ANCOVAa & ANOVA & ANCOVAa \\
\hline $\operatorname{Ln}(k)$ & $\begin{array}{r}-1.67 \\
(0.38)\end{array}$ & $\begin{array}{r}-2.17 \\
(0.34)\end{array}$ & $\begin{array}{l}0.90 \\
\quad(0.352)\end{array}$ & $\begin{array}{l}0.23 \\
\quad(0.636)\end{array}$ & $\begin{array}{r}-1.90 \\
(0.33)\end{array}$ & $\begin{array}{r}-1.88 \\
(0.429)\end{array}$ & $\begin{array}{l}0.003 \\
(0.972)\end{array}$ & $\begin{array}{l}0.09 \\
\quad(0.767)\end{array}$ & $\begin{array}{l}0.18 \\
\quad(0.677)\end{array}$ & $\begin{array}{l}0.13 \\
\quad(0.725)\end{array}$ \\
\hline NImp & $\begin{array}{l}33.2 \\
(3.8)\end{array}$ & $\begin{array}{l}27.1 \\
\quad(3.6)\end{array}$ & $\begin{array}{l}1.31 \\
\quad(0.262)\end{array}$ & $\begin{array}{l}0.41 \\
\quad(0.526)\end{array}$ & $\begin{array}{l}31.6 \\
(4.2)\end{array}$ & $\begin{array}{l}29.5 \\
(3.5)\end{array}$ & $\begin{array}{l}0.17 \\
\quad(0.684)\end{array}$ & $\begin{array}{l}0.46 \\
\quad(0.502)\end{array}$ & $\begin{array}{l}0.053 \\
(0.820)\end{array}$ & $\begin{array}{l}0.24 \\
\quad(0.625)\end{array}$ \\
\hline$\beta b$ & $\begin{array}{l}0.70 \\
\quad(0.08-1.0)\end{array}$ & $\begin{array}{l}0.78 \\
\quad(0.35-0.98)\end{array}$ & $\begin{array}{l}0.95 \\
(0.338)\end{array}$ & $\begin{array}{l}0.82 \\
\quad(0.374) \mathrm{c}\end{array}$ & $\begin{array}{l}0.62 \\
\quad(0.08-0.97)\end{array}$ & $\begin{array}{l}0.80 \\
\quad(0.14-1.0)\end{array}$ & $\begin{array}{l}1.25 \\
(0.274)\end{array}$ & $\begin{array}{l}1.55 \\
(0.223) \mathrm{C}\end{array}$ & $\begin{array}{l}0.09 \\
(0.765)\end{array}$ & $\begin{array}{l}0.00 \\
\quad(0.999) \mathrm{c}\end{array}$ \\
\hline$\delta \mathrm{b}$ & $\begin{array}{l}0.97 \\
\quad(0.83-1.0)\end{array}$ & $\begin{array}{l}0.98 \\
\quad(0.78-1.0)\end{array}$ & $\begin{array}{l}0.44 \\
\quad(0.511)\end{array}$ & $\begin{array}{l}0.002 \\
(0.967) \mathrm{c}\end{array}$ & $\begin{array}{l}0.99 \\
\quad(0.83-1.0)\end{array}$ & $\begin{array}{l}0.97 \\
\quad(0.78-1.0)\end{array}$ & $\begin{array}{l}1.19 \\
(0.285)\end{array}$ & $\begin{array}{l}1.21 \\
\quad(0.282) \mathrm{c}\end{array}$ & $\begin{array}{l}1.09 \\
(0.306)\end{array}$ & $\begin{array}{l}1.66 \\
(0.208) c\end{array}$ \\
\hline PB & $\begin{array}{l}9.19 \\
(1.60)\end{array}$ & $\begin{array}{l}7.00 \\
(1.34)\end{array}$ & $\begin{array}{l}1.20 \\
(0.283)\end{array}$ & $\begin{array}{l}1.00 \\
(0.325)\end{array}$ & $\begin{array}{l}9.48 \\
(1.86)\end{array}$ & $\begin{array}{l}7.13 \\
(1.19)\end{array}$ & $\begin{array}{l}1.14 \\
(0.295)\end{array}$ & $\begin{array}{l}1.10 \\
(0.303)\end{array}$ & $\begin{array}{l}0.31 \\
\quad(0.580)\end{array}$ & $\begin{array}{l}0.003 \\
(0.956)\end{array}$ \\
\hline HL-IPS & $\begin{array}{l}41.5 \\
(7.5)\end{array}$ & $\begin{array}{l}46.5 \\
\quad(11.4)\end{array}$ & $\begin{array}{l}0.22 \\
\quad(0.641)\end{array}$ & & $\begin{array}{l}49.3 \\
(8.6)\end{array}$ & $\begin{array}{l}38.7 \\
(9.5)\end{array}$ & $\begin{array}{l}1.24 \\
(0.375)\end{array}$ & & $\begin{array}{l}5.29 \\
\quad(0.029) *\end{array}$ & \\
\hline
\end{tabular}

Values are reported as the mean (SE), unless otherwise indicated.

aAge and BIS-total scores were added as covariates.

${ }^{b}$ Due to violation of normality, median (range) is shown instead of mean (SE). The rank transform procedure was used to test for main effects and interactions.

${ }^{c}$ A nonparametric equivalent of ANCOVA, as discussed in the study by Quade (1967), was used. Here the resulting $F$ statistic and $p$ value are shown. $* p<0.05$. 

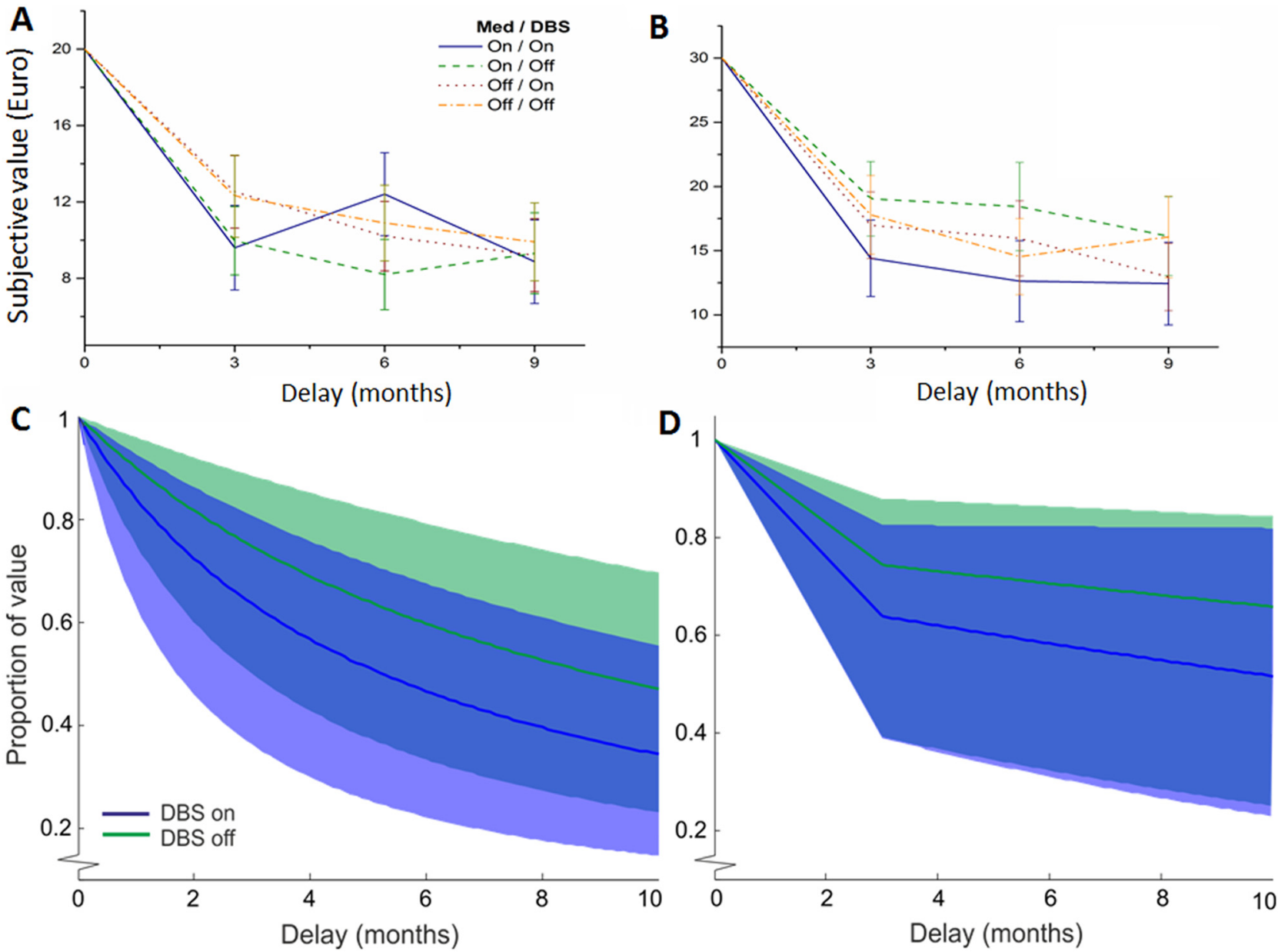

Figure 4. $\boldsymbol{A}, \boldsymbol{B}$, Discounting curves per medication/DBS state subgroup for $€ 20(\boldsymbol{A})$ and $€ 30(\boldsymbol{B})$, based on the indifference point at 3, 6, and 9 months. Error bars show SEs. $\boldsymbol{C}$, Plots of the hyperbolic model in the on-DBS and off-DBS states, based on the median $k$-value. Shaded areas show the 25th and 75th percentile range. $\boldsymbol{D}$, Plots of the quasi-hyperbolic model in the on-DBS and off-DBS state based on the median $\beta$ and $\delta$ values. The initial linear decline represents present bias and is determined by the $\beta$ parameter, whereas the subsequent exponential curve represents "patience" and is determined by the $\delta$ parameter. Shaded areas show the 25 th to 75 th percentile range.

medication/DBS state. When adding age and the BIStotal score as covariates in an additional ANCOVA, THE main and interaction effects of DBS and medication states on any of the discounting parameters remained nonsignificant (DBS state: $\ln (k): F_{(1,28)}=0.23, p=0.636, \eta^{2}=$ 0.009; NImp: $F_{(1,28)}=0.41, p=0.526, \eta^{2}=0.018 ; \beta$ : $F_{(1,28)}=0.819, p=0.37, \eta^{2}=0.029 ; \delta: F_{(1,28)}=0.002$, $p=0.967, \eta^{2}=<0.001 ;$ PB: $F_{(1,28)}=1.00, p=0.325$, $\eta^{2}=0.037$; Table 2).

To calculate the probability that the null hypothesis (no effect of DBS on delay discounting) is true given our data $\left(p\left(H_{0} \mid D\right)\right)$, we used a Bayesian approach developed by Wagenmakers (2007) and also described in detail in a tutorial by Masson (2011). We used the Bayesian information criterion to calculate the posterior probability $p\left(H_{0} \mid D\right)$, with the assumption that the null and alternative hypotheses are equally likely. The results are presented in Table 3. We found $p\left(H_{0} \mid D\right)$ values ranging between 0.73 and 0.81 , indicating positive evidence in favor of the null hypothesis, as suggested by Raftery (1995).
Some patients were treated with dopamine agonists instead of, or in addition to, L-dopa. As dopamine agonists are associated with impulsive behavior (Zurowski and O'Brien, 2015), we checked for differences between the DBS groups in the LED when considering only patients who receive dopamine agonists (LED agonists; Table 4). In each of the DBS groups, five patients used dopamine agonists, with no significant difference in LED agonist levels between groups $(U=110.50, p=0.561$, $r=0.13$ ).

The Holt-Laury task was added as a control for the fact that impulsive behavior sometimes correlates with altered risk preferences (Kalenscher and Pennartz, 2008). There were no significant main effects of DBS or medication on Holt-Laury task scores (DBS state: $F_{(1,28)}=0.22, p=$ $0.641, \eta^{2}=0.01$; medication: $F_{(1,28)}=1.24, p=0.275$, $\eta^{2}=0.04$ ), suggesting no effect of DBS and/or medication on risk attitude. Note, though, that we found a significant interaction effect of DBS and medication state on HL-IPs $\left(F_{(1,28)}=5.29, p=0.029, \eta^{2}=0.16\right)$. However, 


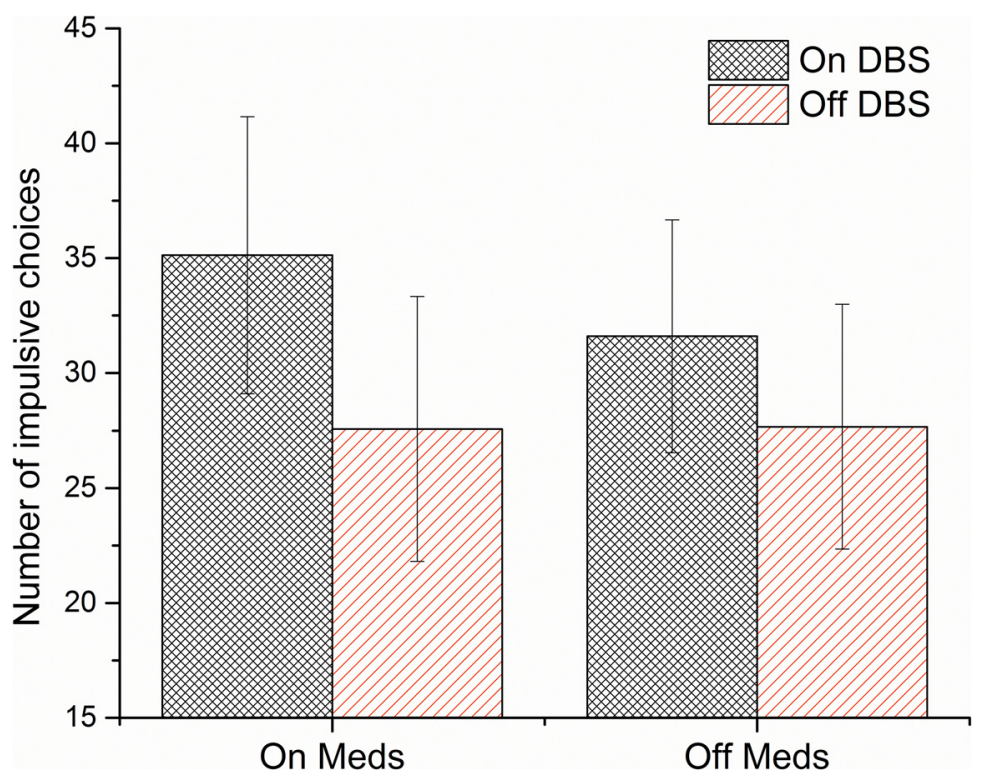

Figure 5. The total number of impulsive choices (smaller, sooner reward) for each DBS and medication state. Error bars show SDs.

when using the complete sample of 40 patients, the interaction effect of DBS and medication state on HL-IPs failed to reach significance $\left(F_{(1,39)}=1.00, p=0.325, \eta^{2}=\right.$ 0.027 ). Note that a relatively large number of patients showed an inconsistent choice pattern (i.e., switching more than once between the risky and safe gamble), with $47,5 \%$ making at least one error (one more switch) and $30 \%$ having at least two errors, compared with the numbers mentioned in the original article on the Holt-Laury task (Holt and Laury, 2002), where only $13.2 \%$ of the participants made at least one error.

\section{Discussion}

In this study, we aimed to investigate the effect of STNDBS on impulsive decision-making, using a delaydiscounting paradigm. We found no evidence for an effect of either STN-DBS or medication on delay-discounting behavior, a commonly used measure of impulsive choice. Although we found a significant effect of the interaction of DBS and medication state on risk aversion, this effect did

Table 3. Bayesian posterior probabilities for the hypothesis that there is an effect $\left(\mathrm{H}_{1}\right)$, or for the hypothesis that there is no effect $\left(\mathrm{H}_{0}\right)$, of DBS on discounting measures, given our data

\begin{tabular}{lllll}
\hline & NImp & Ln(k) & $\boldsymbol{\beta}$ & $\boldsymbol{\delta}$ \\
$p\left(\mathrm{H}_{0} \mid \mathrm{D}\right)$ & 0.731 & 0.774 & 0.765 & 0.813 \\
$p\left(\mathrm{H}_{1} \mid \mathrm{D}\right)$ & 0.269 & 0.226 & 0.235 & 0.187 \\
\hline
\end{tabular}

Table 4. Number of participants receiving dopamine agonists, and the LED agonists of the dopamine agonists used, per DBS group

\begin{tabular}{llll}
\hline & $\mathbf{N}$ & LED agonists & Average LED agonists \\
DBS on & 5 & 595 & 119.0 \\
DBS off & 5 & 837 & 167.4
\end{tabular}

not hold when all participants were included in the analysis. In addition, due to the relatively large number of errors the participants made in this task, we refrain from further interpretation of this finding.

Our findings are in line with a study by Torta et al. (2012), who investigated the effects of STN-DBS on delay aversion. Twenty-one PD patients with STN-DBS turned on and off (patients were off medication) performed the Cambridge Gambling Task, which measured both risk behavior and delay aversion, and filled out questionnaires assessing self-reported delay aversion, delay discounting, and impulsivity. The authors found no effects of stimulation on delay aversion or task behavior, although patients self-reported a higher feeling of impulsivity in the offstimulation state. Thus, while increased levels of delay discounting have been associated with several impulse control disorders, such as substance abuse, attention deficit hyperactivity disorder, as well as pathological gambling and overeating (Bickel et al., 2012)-behaviors often shown by PD patients in response to their treatmentthere is no evidence so far that STN-DBS alters delay discounting.

Although the development of ICDs is often attributed to side effects of dopaminergic medication (Voon and Fox, 2007; Voon et al., 2011a,b; Poletti et al., 2013), several studies point toward a potential role of STN-DBS in the development of ICDs in PD patients (Hälbig et al., 2009; Lim et al., 2009; Moum et al., 2012). However, it has been argued that the development of ICDs after STN-DBS onset may be an indirect consequence of disease history and treatment, as they may result from long-term alterations of frontolimbic structures, which are presumed to be involved in ICDs (Brewer and Potenza, 2008), due to disease progress and long-term medication use (Moum et al., 2012). Because ICDs themselves are considered to be chronic disorders, a short change in DBS state, as 
applied here, after several months of chronic stimulation might not be sufficient to uncover potential long-term effects leading to the development of ICDs. This would be in line with findings pointing at an increase in cognitive impulsivity reported by both patients and relatives 3 months after STN-DBS onset compared with a baseline taken before STN-DBS onset (Pham et al., 2015), but would be contradictory to the above-mentioned selfreported increase in impulsivity in a short-term off-state compared with scores in the DBS-on state (Torta et al., 2012). Although the motor effects of STN-DBS are often visible within minutes, cognitive effects of STN-DBS on impulsive decision-making might not be visible in the short term. For example, as reward learning seems to be affected by STN-DBS, perhaps experiences with rewards after STN-DBS onset influence subsequent choice behavior that could lead to the development of ICDs in a subgroup of patients. Future studies need to monitor longterm changes in delay discounting in particular, and impulsivity in general, after STN-DBS treatment onset.

Impulsivity itself is considered a multifaceted construct (Evenden, 1999; Kalenscher et al., 2006), with one subtype being defined as impulsive action (the inability to inhibit a prepotent response) and another subtype defined as impulsive choice (preferring a smaller, more immediate reward over a larger, more delayed reward; Winstanley et al., 2004; Kalenscher and Pennartz, 2008; Robinson et al., 2009). Motor impulsivity is commonly assessed with reaction time tasks, in which motor responses need to be inhibited either before ("waiting") or during ("stopping") execution, whereas choice impulsivity is often assessed with an intertemporal choice task, in which participants make repetitive choices between a smaller/sooner and larger/later (often monetary) reward. Several studies have dissociated the cognitive and neural bases of these two types of impulsivity (Winstanley et al., 2004; Van den Bergh et al., 2006; Broos et al., 2012). So far, studies have uncovered the effects of STN-DBS on motor impulsivity (Witt et al., 2004; Frank et al., 2007; Aleksandrova et al., 2013), which is in line with literature supporting the involvement of the STN in controlling the threshold for responding in situations with high conflict (i.e., when two choice options are relatively similar in value; Baunez and Robbins, 1997; Baunez et al., 2001; Desbonnet et al., 2004; Frank, 2006; Cavanagh et al., 2011). With regard to reward processing and decision-making, STN-DBS seems to mainly influence reward learning (Serranová et al., 2011; van Wouwe et al., 2011) and the evaluation of losses (Rogers et al., 2011), but, to the best of our knowledge, there is no evidence so far of an effect of STN-DBS on risky decision-making (Brandt et al., 2015).

One concern with our study is the small sample size, and, by consequence, the low statistical power. We cannot reject the possibility that we missed a small effect of STN-DBS on delay discounting because we lacked the statistical power to detect it. However, our Bayesian analysis showed positive evidence in favor of the null hypothesis. This suggests that the effect size is either very small or nonexistent. Therefore, we can conclude with some confidence that, if there were a short-term effect of STN-
DBS on delay discounting, it would be miniscule and probably negligible.

Note that we started off with a small pilot experiment to check whether our task was suitable for repeated measures, as this would greatly increase power. However, we found that patients often made stereotypical, repetitive choices on subsequent repetitions of the task, which was supported by anecdotal remarks about their choice behavior and strategy (e.g., they would ask why they had to do the same task again; or they specifically commented on the fact that they would remember their choices in the previous task, and aimed to copy their own choices). For this reason, we opted against using a repeated-measures design.

Additionally, we would like to note that, although highly undesirable, underpowered statistics are frequently unavoidable in studies with clinical populations; due to the difficulty of finding a sufficient number of patients meeting the inclusion criteria, patient samples in medical studies are often smaller than desired. Nevertheless, despite the admittedly low power, we believe that our results are of significance to other scientists studying the effects of PD treatment on impulsive decision-making. To prevent the so-called "file drawer effect" (i.e., publication biases due to potentially informative studies ending up not being published due to nonsignificant findings; Sterling et al., 1995; Hopewell et al., 2009; Song et al., 2009), we would like to make our findings accessible to researchers interested in similar research problems.

In conclusion, we failed to demonstrate a significant effect of STN-DBS on delay discounting. Although an absence of evidence is not evidence of absence, calling for interpretative caution, this could potentially imply that STN-DBS effects on delay discounting do not exist. From a clinical perspective, this study provides evidence for a lack of negative cognitive side effects of STN-DBS in the form of altered intertemporal decision-making. Even if a small effect of STN-DBS on delay discounting existed, a risk of slightly altered decision-making likely does not weigh the same as the benefits of STN-DBS on motor functioning. Our findings, therefore, underscore the clinical safety of DBS-STN as a therapeutic treatment.

\section{References}

Aleksandrova LR, Creed MC, Fletcher PJ, Lobo DSS, Hamani C, Nobrega JN (2013) Deep brain stimulation of the subthalamic nucleus increases premature responding in a rat gambling task. Behav Brain Res 245:76-82. CrossRef

Ardouin C, Voon V, Worbe Y, Abouazar N, Czernecki V, Hosseini H, Pelissolo A, Moro E, Lhommée E, Lang AE, Agid Y, Benabid AL, Pollak P, Mallet L, Krack P (2006) Pathological gambling in Parkinson's disease improves on chronic subthalamic nucleus stimulation. Mov Disord 21:1941-1946. CrossRef

Ardouin, C, Chereau, I, Llorca, PM, Lhommee, E, Durif, F, Pollak, P, Krack, P \& Mal, G.E.C. (2009) Assessment of hyper- and hypodopaminergic behaviors in Parkinson's disease. Rev Neurol-France 165, 845-856. Medline

Bandini F, Primavera A, Pizzorno M, Cocito L (2007) Using STN DBS and medication reduction as a strategy to treat pathological gambling in Parkinson's disease. Parkinsonism Relat Disord 13:369371. CrossRef 
Baunez C, Robbins TW (1997) Bilateral lesions of the subthalamic nucleus induce multiple deficits in an attentional task in rats. Eur $\mathrm{J}$ Neurosci 9:2086-2099. Medline

Baunez C, Humby T, Eagle DM, Ryan LJ, Dunnett SB, Robbins TW (2001) Effects of STN lesions on simple vs choice reaction time tasks in the rat: preserved motor readiness, but impaired response selection. Eur J Neurosci 13:1609-1616. CrossRef

Beck, AT, Steer, RA, Ball, R \& Ranieri, WF (1996) Comparison of Beck Depression Inventories-IA and -II in psychiatric outpatients. J Pers Assess 67, 588-597.

Bickel WK, Jarmolowicz DP, Mueller ET, Koffarnus MN, Gatchalian KM (2012) Excessive discounting of delayed reinforcers as a transdisease process contributing to addiction and other diseaserelated vulnerabilities: emerging evidence. Pharmacol Ther 134: 287-297. CrossRef

Brandt J, Rogerson M, Al-Joudi H, Reckess G, Shpritz B, Umeh CC, Aljehani N, Mills K, Mari Z (2015) Betting on DBS: effects of subthalamic nucleus deep brain stimulation on risk taking and decision making in patients with Parkinson's disease. Neuropsychology 29:622-631. CrossRef

Brewer JA, Potenza MN (2008) The neurobiology and genetics of impulse control disorders: relationships to drug addictions. Biochem Pharmacol 75:63-75. CrossRef

Broen M, Duits A, Visser-Vandewalle V, Temel Y, Winogrodzka A (2011) Impulse control and related disorders in Parkinson's disease patients treated with bilateral subthalamic nucleus stimulation: a review. Parkinsonism Relat Disord 17:413-417. CrossRef

Broos N, Schmaal L, Wiskerke J, Kostelijk L, Lam T, Stoop N, Weierink L, Ham J, de Geus EJC, Schoffelmeer ANM, van den Brink W, Veltman DJ, de Vries TJ, Pattij T, Goudriaan AE (2012) The relationship between impulsive choice and impulsive action: a cross-species translational study. PLoS One 7:e36781. CrossRef

Cardinal RN, Pennicott DR, Sugathapala CL, Robbins TW, Everitt BJ (2001) Impulsive choice induced in rats by lesions of the nucleus accumbens core. Science 292:2499-2501. CrossRef Medline

Cavanagh JF, Wiecki TV, Cohen MX, Figueroa CM, Samanta J, Sherman SJ, Frank MJ (2011) Subthalamic nucleus stimulation reverses mediofrontal influence over decision threshold. Nat Neurosci 14:1462-1467. CrossRef

Chang JY, Shi LH, Luo F, Zhang WM, Woodward DJ (2007) Studies of the neural mechanisms of deep brain stimulation in rodent models of Parkinson's disease. Neurosci Biobehav Rev 31:643657. CrossRef

Clare, S, Helps, S \& Sonuga-Barke, EJ (2010) The quick delay questionnaire: a measure of delay aversion and discounting in adults. Attention deficit and hyperactivity disorders 2, 43-48. Medline

Demetriades P, Rickards H, Cavanna AE (2011) Impulse control disorders following deep brain stimulation of the subthalamic nucleus in Parkinson's disease: clinical aspects. Parkinsons Dis 2011:658415. CrossRef

Desbonnet L, Temel Y, Visser-Vandewalle V, Blokland A, Hornikx V, Steinbusch HWM (2004) Premature responding following bilateral stimulation of the rat subthalamic nucleus is amplitude and frequency dependent. Brain Res 1008:198-204. CrossRef

Deuschl G, Schade-Brittinger C, Krack P, Volkmann J, Schäfer H, Bötzel K, Daniels C, Deutschländer A, Dillmann U, Eisner W, Gruber D, Hamel W, Herzog J, Hilker R, Klebe S, Kloss M, Koy J, Krause M, Kupsch A, Lorenz D, et al. (2006) A randomized trial of deep-brain stimulation for Parkinson's disease. N Engl J Med 355:896-908. CrossRef

Evenden JL (1999) Varieties of impulsivity. Psychopharmacology 146:348-361. Medline

Filippin A, Crosetto P (2014) A reconsideration of gender differences in risk attitudes. Manage Sci. Advance online publication. Retrieved 1 May 2016. doi:10.1287/mnsc.2015.2294.

Frank MJ (2006) Hold your horses: a dynamic computational role for the subthalamic nucleus in decision making. Neural Netw 19:11201136. CrossRef Medline
Frank MJ, Samanta J, Moustafa AA, Sherman SJ (2007) Hold your horses: impulsivity, deep brain stimulation, and medication in parkinsonism. Science 318:1309-1312. CrossRef Medline

Goetz CG, Tilley BC, Shaftman SR, Stebbins GT, Fahn S, MartinezMartin P, Poewe W, Sampaio C, Stern MB, Dodel R, Dubois B, Holloway R, Jankovic J, Kulisevsky J, Lang AE, Lees A, Leurgans S, LeWitt PA, Nyenhuis D, Olanow CW, et al. (2008) Movement Disorder Society-sponsored revision of the Unified Parkinson's Disease Rating Scale (MDS-UPDRS): scale presentation and clinimetric testing results. Mov Disord 23:2129-2170. CrossRef

Hälbig TD, Tse W, Frisina PG, Baker BR, Hollander E, Shapiro H, Tagliati M, Koller WC, Olanow CW (2009) Subthalamic deep brain stimulation and impulse control in Parkinson's disease. Eur $\mathrm{J}$ Neurol 16:493-497. CrossRef Medline

Hardisty DJ, Thompson KF, Krantz DH, Weber EU (2013) How to measure time preferences: an experimental comparison of three methods. Judgm Decis Mak 8:236-249.

Haynes WIA, Haber SN (2013) The organization of prefrontalsubthalamic inputs in primates provides an anatomical substrate for both functional specificity and integration: implications for basal ganglia models and deep brain stimulation. J Neurosci 33: 4804-4814. CrossRef

Holt CA, Laury SK (2002) Risk aversion and incentive effects. Am Econ Rev 92:1644-1655. CrossRef

Hopewell S, Loudon K, Clarke MJ, Oxman AD, Dickersin K (2009) Publication bias in clinical trials due to statistical significance or direction of trial results. Cochrane Database Syst Rev (1): MR000006.

Kalenscher T, Pennartz CMA (2008) Is a bird in the hand worth two in the future? The neuroeconomics of intertemporal decisionmaking. Prog Neurobiol 84:284-315. CrossRef Medline

Kalenscher T, Ohmann T, Güntürkün O (2006) The neuroscience of impulsive and self-controlled decisions. Int J Psychophysiol 62: 203-211. CrossRef Medline

Kheramin S, Body S, Mobini S, Ho MY, Velazquez-Martinez DN, Bradshaw CM, Szabadi E, Deakin JFW, Anderson IM (2002) Effects of quinolinic acid-induced lesions of the orbital prefrontal cortex on inter-temporal choice: a quantitative analysis. Psychopharmacology 165:9-17.

Kirby KN, Maraković NN (1996) Delay-discounting probabilistic rewards: rates decrease as amounts increase. Psychon Bull Rev 3:100-104. CrossRef

Laibson D (1997) Golden eggs and hyperbolic discounting. Q J Econ 112:443-477. CrossRef

Lambert C, Zrinzo L, Nagy Z, Lutti A, Hariz M, Foltynie T, Draganski B, Ashburner J, Frackowiak R (2012) Confirmation of functional zones within the human subthalamic nucleus: patterns of connectivity and sub-parcellation using diffusion weighted imaging. Neuroimage 60:83-94. CrossRef

Lesieur, HR \& Blume, S.B. (1987) The South Oaks Gambling Screen (SOGS): a new instrument for the identification of pathological gamblers. The American journal of psychiatry 144, 1184-1188. Medline

Li Q, Ke Y, Chan DCW, Qian ZM, Yung KKL, Ko H, Arbuthnott GW, Yung WH (2012) Therapeutic deep brain stimulation in Parkinsonian rats directly influences motor cortex. Neuron 76:1030-1041. CrossRef Medline

Li S, Arbuthnott GW, Jutras MJ, Goldberg JA, Jaeger D (2007) Resonant antidromic cortical circuit activation as a consequence of high-frequency subthalamic deep-brain stimulation. J Neurophysiol 98:3525-3537. CrossRef

Lim SY, O'Sullivan SS, Kotschet K, Gallagher DA, Lacey C, Lawrence AD, Lees AJ, O'Sullivan DJ, Peppard RF, Rodrigues JP, Schrag A, Silberstein P, Tisch S, Evans AH (2009) Dopamine dysregulation syndrome, impulse control disorders and punding after deep brain stimulation surgery for Parkinson's disease. J Clin Neurosci 16: 1148-1152. CrossRef

Lucas, JA, Ivnik, RJ, Smith, GE \& Bohac, DL (1998) Normative data for the Mattis Dementia Rating Scale. Arch Clin Neuropsych, 13, 41-42. Medline 
Masson ME (2011) A tutorial on a practical Bayesian alternative to null-hypothesis significance testing. Behav Res Methods 43:679690. CrossRef Medline

Mattis S. Dementia Rating Scale: Professional Manual. Odessa, FL: Psychological Assessment Resources; 1988.

Maurice N, Deniau JM, Glowinski J, Thierry AM (1998) Relationships between the prefrontal cortex and the basal ganglia in the rat: physiology of the corticosubthalamic circuits. J Neurosci 18:95399546.

Mazur JE (1984) Tests of an equivalence rule for fixed and variable reinforcer delays. J Exp Psychol Anim Behav Process 10:426-436. CrossRef

McCracken CB, Grace AA (2007) High-frequency deep brain stimulation of the nucleus accumbens region suppresses neuronal activity and selectively modulates afferent drive in rat orbitofrontal cortex in vivo. J Neurosci 27:12601-12610. CrossRef

Montgomery EB Jr, Gale JT (2007) Mechanisms of action of deep brain stimulation (DBS). Neurosci Biobehav Rev 32:388-407. CrossRef Medline

Moum SJ, Price CC, Limotai N, Oyama G, Ward H, Jacobson C, Foote KD, Okun MS (2012) Effects of STN and GPi deep brain stimulation on impulse control disorders and dopamine dysregulation syndrome. PLoS One 7:e29768. CrossRef

Nambu A, Tokuno H, Takada M (2002) Functional significance of the cortico-subthalamo-pallidal "hyperdirect" pathway. Neurosci Res 43:111-117. Medline

Parent A, Hazrati LN (1995a) Functional-anatomy of the basal ganglia. I. The cortico-basal ganglia-thalamo-cortical loop. Brain Res Rev 20:91-127. Medline

Parent A, Hazrati LN (1995b) Functional-anatomy of the basal ganglia. II. The place of subthalamic nucleus and external pallidum in basal ganglia circuitry. Brain Res Rev 20:128-154. Medline

Pham U, Solbakk AK, Skogseid IM, Toft M, Pripp AH, Konglund AE, Andersson S, Haraldsen IR, Aarsland D, Dietrichs E, Malt UF (2015) Personality changes after deep brain stimulation in Parkinson's disease. Parkinsons Dis 2015:490507 CrossRef

Poletti M, Logi C, Lucetti C, Del Dotto P, Baldacci F, Vergallo A, Ulivi M, Del Sarto S, Rossi G, Ceravolo R, Bonuccelli U (2013) A single-center, cross-sectional prevalence study of impulse control disorders in Parkinson disease: association with dopaminergic drugs. J Clin Psychopharmacol 33:691-694. CrossRef

Quade D (1967) Rank analysis of covariance. J Am Stat Assoc 62:1187-1200. CrossRef

Raftery AE (1995) Bayesian model selection in social research. Sociol Methodol 25:111-163. CrossRef

Raja M, Bentivoglio AR (2012) Impulsive and compulsive behaviors during dopamine replacement treatment in Parkinson's Disease and other disorders. Curr Drug Saf 7:63-75. CrossRef

Robinson ESJ, Eagle DM, Economidou D, Theobald DEH, Mar AC, Murphy ER, Robbins TW, Dalley JW (2009) Behavioural characterisation of high impulsivity on the 5-choice serial reaction time task: specific deficits in "waiting" versus "stopping." Behav Brain Res 196:310-316. CrossRef

Rogers RD, Wielenberg B, Wojtecki L, Elben S, Campbell-Meiklejohn D, Schnitzler A (2011) Deep brain stimulation of the subthalamic nucleus transiently enhances loss-chasing behaviour in patients with Parkinson's Disease. Exp Neurol 231:181-189. CrossRef

Schmidt, R, Freidl, W, Fazekas, F, Reinhart, B, Grieshofer, P, Koch, M, Eber, B, Schumacher, M, Polmin, K \& Lechner, H (1994) The Mattis-Dementia-Rating-Scale - Normative Data from 1,001 Healthy-Volunteers. Neurology 44, 964-966. CrossRef
Serranová $T$, Jech $R$, Dušek $P$, Sieger $T$, Ru žička $F$, Urgošík $D$, Rưžička E (2011) Subthalamic nucleus stimulation affects incentive salience attribution in Parkinson's disease. Mov Disord 26: 2260-2266. CrossRef Medline

Song FJ, Parekh-Bhurke S, Hooper L, Loke YK, Ryder JJ, Sutton AJ, Hing CB, Harvey I (2009) Extent of publication bias in different categories of research cohorts: a meta-analysis of empirical studies. BMC Med Res Methodol 9:79. CrossRef

Spinella, M (2007) Normative data and a short form of the Barratt Impulsiveness Scale. The International journal of neuroscience 117, 359-368. Medline

Sterling TD, Rosenbaum WL, Weinkam JJ (1995) Publication decisions revisited: the effect of the outcome of statistical tests on the decision to publish and vice-versa. Am Stat 49:108-112. CrossRef

Torta DME, Vizzari V, Castelli L, Zibetti M, Lanotte M, Lopiano L, Geminiani G (2012) Impulsivities and Parkinson's disease: delay aversion is not worsened by deep brain stimulation of the subthalamic nucleus. PLoS One 7:e43261. CrossRef

Van den Bergh F, Spronk M, Ferreira L, Bloemarts E, Groenink L, Olivier B, Oosting R (2006) Relationship of delay aversion and response inhibition to extinction learning, aggression, and sexual behaviour. Behav Brain Res 175:75-81. CrossRef Medline

van Wouwe NC, Ridderinkhof KR, van den Wildenberg WPM, Band GPH, Abisogun A, Elias WJ, Frysinger R, Wylie SA (2011) Deep brain stimulation of the subthalamic nucleus improves rewardbased decision-learning in Parkinson's disease. Front Hum Neurosci 5:30. CrossRef

Voon V, Fox SH (2007) Medication-related impulse control and repetitive behaviors in Parkinson Disease. Arch Neurol 64:10891096. CrossRef Medline

Voon V, Gao J, Brezing C, Symmonds M, Ekanayake V, Fernandez H, Dolan RJ, Hallett M (2011a) Dopamine agonists and risk: impulse control disorders in Parkinson's; disease. Brain 134:1438-1446. CrossRef Medline

Voon V, Mehta AR, Hallett M (2011b) Impulse control disorders in Parkinson's disease: recent advances. Curr Opin Neurol 24:324330. CrossRef Medline

Wagenmakers EJ (2007) A practical solution to the pervasive problems of $p$ values. Psychon Bull Rev 14:779-804. Medline

Weintraub D (2008) Dopamine and impulse control disorders in Parkinson's disease. Annal Neurol 64 [Suppl. 2]:S93-S100. CrossRef

Wichmann T, DeLong MR (2006) Deep brain stimulation for neurologic and neuropsychiatric disorders. Neuron 52:197-204. CrossRef Medline

Winstanley CA, Dalley JW, Theobald DEH, Robbins TW (2004) Fractionating impulsivity: contrasting effects of central 5-HT depletion on different measures of impulsive behavior. Neuropsychopharmacology 29:1331-1343. CrossRef

Witjas T, Baunez C, Henry JM, Delfini M, Regis J, Cherif AA, Peragut JC, Azulay JP (2005) Addiction in Parkinson's disease: impact of subthalamic nucleus deep brain stimulation. Mov Disord 20:10521055. CrossRef Medline

Witt K, Pulkowski U, Herzog J, Lorenz D, Hamel W, Deuschl G, Krack $P$ (2004) Deep brain stimulation of the subthalamic nucleus improves cognitive flexibility but impairs response inhibition in Parkinson disease. Arch Neurol 61:697-700. CrossRef

Zurowski M, O'Brien JD (2015) Developments in impulse control behaviours of Parkinson's disease. Curr Opin Neurol 28:387-392. CrossRef Medline 